\title{
OS IDOSOS E AS INSTITUIÇÕES ASILARES DO MUNICÍPIO DE CAMPINAS ${ }^{1}$
}

\author{
Akemi Yamamoto ${ }^{2}$ \\ Maria José D'Elboux Diogo ${ }^{3}$
}

Yamamoto A, Diogo MJD. Os idosos e as instituições asilares do município de Campinas. Rev Latino-am Enfermagem 2002 setembro-outubro; 10(5):660-6.

Este estudo tem como objetivo caracterizar as instituições asilares de Campinas quanto aos seus residentes, recursos humanos e rotinas realizadas. Foram investigadas seis instituições de caráter privado, com residentes, em sua maioria dependentes, e recursos humanos insuficientes qualitativa e quantitativamente. Foi possivel verificar que a capacitação dos profissionais, na área de geriatria e gerontologia, em particular, da equipe de enfermagem, é imprescindível para a melhoria da assistência prestada aos idosos.

DESCRITORES: asilos para idosos, recursos humanos de enfermagem, geriatria, gerontologia

\section{THE ELDERLY AND ASYLUMS AT THE MUNICIPALITY OF CAMPINAS, BRAZIL}

This study aimed at characterizing the asylums at the municipality of Campinas regarding their residents, human resources and routines. Authors investigated six private institutions with residents, whose majority were dependent and with quantitatively and qualitatively insufficient human resources. It was possible to verify the capacitation of the health professionals in the areas of geriatrics and gerontology, in particular, as well as of the nursing team that is really important to the improvement of the care provided to the elderly.

DESCRIPTORS: asylum, nursing human resources, geriatrics, gerontology

\section{LOS ANCIANOS Y LAS INSTITUCIONES ASILARES DEL MUNICIPIO DE CAMPINAS}

Este estudio tiene como objetivo caracterizar las instituciones asilares de Campinas, en relación con los residentes, recursos humanos y rutinas realizadas. Fueron investigadas seis instituciones de carácter privado, que abrigan residentes cuya mayoría es dependiente y que tienen recursos humanos insuficientes cualitativa y cuantitativamente. Fue posible verificar que la capacitación de los profesionales del área de geriatría y gerontología y en particular del equipo de enfermería, es imprescindible para la mejoría de la atención a los ancianos.

DESCRIPTORES: asilos para ancianos, recursos humanos de enfermería, geriatría, gerontología

\footnotetext{
${ }^{1}$ Parte do trabalho de Iniciação Científica financiado pela FAPESP (processo no 99/08420-0); ${ }^{2}$ Aluna do Curso de Graduação em Enfermagem, Bolsista de Iniciação Científica da FAPESP, e-mail: akemyamamoto@yahoo.com.br; ${ }^{3}$ Orientadora, Professor Assistente Doutor, Título de Especialista em Gerontologia Social pela SBGG, e-mail: mariadio@uol.com.br. Faculdade de Ciências Médicas da Universidade Estadual de Campinas
} 


\section{INTRODUÇÃO}

Segundo o Decreto n ${ }^{\circ} 1.948$, de 03 de julho de $1996^{(1)}$, artigo $3^{\circ}$, existem formas distintas de atendimento aos idosos: a modalidade asilar, "atendimento, em regime de internato, ao idoso sem vínculo familiar ou sem condições de prover a própria subsistência, de modo a satisfazer as suas necessidades de moradia, alimentação, saúde e convivência social", que rege a vida do mesmo por meio de normas específicas ${ }^{(2)}$, e o ampara civil e socialmente ${ }^{(3)}$; e a modalidade não-asilar, que se compõe de Centro de Convivência, Centro de Cuidados Diurno, Hospital-Dia, Casa-Lar e Oficina Abrigada de Trabalho e destina-se a atender o idoso por determinado período do dia.

Maior importância deveria ser dada a essas últimas, pois possibilitariam ao idoso continuar sob o convívio familiar. A Lei 8.842, de janeiro de $1994^{(4)}$, artigo $4^{\circ}$, parágrafo III, prioriza o atendimento do idoso pelas famílias, ao invés do asilar. Há críticas, contudo, quanto à falta de políticas públicas que sejam condizentes com o discurso governamental; isso se relaciona às poucas verbas e fiscalização ${ }^{(5)}$. A existência de inúmeros fatores, tais como os demográficos, sociais e de saúde, conduzem ao aumento da demanda pela institucionalização.

Na Portaria no 810, de 22 de setembro de 1989, do Ministério da Saúde, estão descritas as normas e padrões para o funcionamento de casas de repouso, clínicas geriátricas e outras instituições destinadas ao atendimento de idosos, quanto à definição, organização, área física e recursos humanos ${ }^{(6)}$. Todavia, muitas instituições funcionam sem estarem sob as condições ideais e, ainda que recebam o aval para funcionarem, "estão longe de atenderem à população idosa"(5).

Alguns autores mencionam a inexistência da equipe multidisciplinar nas instituições, que são compostas por profissionais pouco qualificados ${ }^{(7)}$. Sobre essa questão, particularmente em relação aos profissionais da equipe de enfermagem, nos deparamos freqüentemente com instituições que não contam, em seu quadro, com as diversas categorias da área, mas, sim, voluntários, que realizam procedimentos de competência do auxiliar, do técnico de enfermagem e até mesmo do enfermeiro.

Outrossim, cabe destacar os aspectos legais, dispostos nos Documentos Básicos de Enfermagem ${ }^{(8)}$. Conforme consta no Artigo 15 da Lei n ${ }^{\circ} 5.905$, de 12 de julho de 1973, compete aos Conselhos Regionais de Enfermagem "disciplinar e fiscalizar o exercício profissional, observadas as diretrizes gerais do Conselho Federal". Acresce a essa atividade, a Lei $n^{\circ} 7.498$, de 25 de junho de 1986, que dispõe sobre a regulamentação do exercício da Enfermagem e dá outras providências, em seu Art.2 $2^{\circ}$ : "A Enfermagem e suas atividades auxiliares somente podem ser exercidas por pessoas legalmente habilitadas e inscritas no Conselho Regional de Enfermagem, com jurisdição na área onde ocorre o exercício". O atendente de enfermagem, embora não pertença a qualquer categoria referida no artigo $3^{\circ}$, parágrafo único, da Resolução COFEN-191, pode exercer atividades limitadas, com autorização do Conselho Regional.

No entanto, como as instituições asilares não apresentam o perfil de estabelecimento de assistência à saúde, mas nelas são exercidas ações de promoção, proteção e reabilitação da saúde, a fiscalização sanitária é precária quanto à capacidade legal do agente, ou seja, não ocorre, com o devido rigor, uma fiscalização dos documentos de habilitação inerentes ao âmbito profissional ou ocupacional das pessoas que prestam assistência e cuidados aos residentes.

Ademais, compete também aos órgãos fiscalizadores promover estudos sobre a especialização do profissional de nível médio. Partindo do pressuposto de que as alterações decorrentes do processo de senescência e senilidade exigem qualificação e conhecimentos específicos por parte das pessoas que prestam cuidados aos idosos, a fim de assegurar serviços sem riscos a essa clientela, acreditamos que o profissional, tanto o de nível superior, como o de nível médio, devem ter acesso a sua formação específica, para atuarem junto à população dessa faixa etária. Nesse sentido, o Conselho Regional de Enfermagem de São Paulo desenvolveu trabalhos e, em parceria com o Conselho Federal de Enfermagem, realizou a $1^{\text {a }}$ Oficina de Trabalho para análise e discussão dos resultados dos trabalhos, em abril de $1999^{(9)}$. Embora nos pareça que os campos utilizados para a realização dos estudos não envolveram as instituições asilares, chamamos a atenção para o novo 
perfil epidemiológico e demográfico da população brasileira, que, com certeza, exigirá profissionais de enfermagem especializados na área gerontológica e geriátrica.

A instituição é "fruto das necessidades sociais", sendo objeto de seu controle e, assim, "passível de ser influenciada por ele e modificada segundo suas necessidades"(3). Cabe, portanto, à família, à sociedade e ao Estado assegurar ao idoso sua cidadania e dignidade, bem-estar e direito à vida, segundo a Lei 8.842, artigo $3^{\circ}$, parágrafo I ${ }^{(4)}$.

Tomando o município de Campinas como recorte da realidade nacional, percebemos o aumento da demanda de idosos quanto à institucionalização. Temos observado uma crescente oferta de locais para abrigo de idosos, denominados "casas de repouso", "lares", "pensionatos", "clínicas" e "sociedades". No entanto, ao procurarmos a Prefeitura Municipal de Campinas, verificamos que não existem dados referentes as suas características, e a maioria delas nem sequer possui cadastro, o que dificulta a fiscalização quanto a seu funcionamento, seja por meio de ações municipais, como por parte do Conselho Regional de Enfermagem.

Isso posto, o presente estudo, parte de uma investigação mais ampla em nível de iniciação científica, tem a finalidade de conhecer a realidade das instituições asilares do município de Campinas, para obtenção de informações que subsidiem o desenvolvimento de intervenções junto aos seus dirigentes, com vistas à melhoria da qualidade de vida dos residentes desses locais.

\section{OBJETIVO}

Caracterizar as instituições asilares destinadas a idosos do município de Campinas, quanto aos seus residentes, recursos humanos e rotinas realizadas.

\section{MÉTODO}

Trata-se de um estudo exploratório descritivo, realizado com seis instituições asilares destinadas a idosos, dentre as 13 cadastradas na prefeitura do município de Campinas, São Paulo. Do total das instituições cadastradas, sete foram excluídas: três por se recusarem a participar, e quatro por não serem voltadas ao atendimento de idosos. A amostra reduziu-se, portanto, a seis instituições.

Para a coleta de dados, utilizamos um instrumento construído com base na Portaria $n^{\circ} 810$, mencionada anteriormente e no instrumento utilizado por outros autores $^{(7)}$.

Após autorização dos dirigentes das instituições, visitamos as dependências do local e entrevistamos a pessoa indicada, a qual assinou o termo de consentimento livre e esclarecido.

\section{RESULTADOS E DISCUSSÃO}

Serão apresentados os resultados referentes às instituições que estão identificadas pelas letras $A, B, C$, D, E e F.

Características da instituição

Segundo os dados obtidos, as instituições possuem objetivos assim identificados: das seis instituições, três são voltadas ao atendimento de indivíduos com condições socioeconômicas precárias (C, D e F). As outras três possuem objetivos tanto voltados ao asilamento de religiosas $(E)$ e de indivíduos que não podem ser cuidados pelas famílias $(A)$, quanto à reabilitação em caráter temporário $(\mathrm{B})$.

Quanto ao caráter da instituição, as instituições A, B e C são privadas, embora, particularmente, a instituição $C$ receba doações particulares, além de possuir um convênio com a prefeitura do município. A instituição $D$ é filantrópica e mantém-se através de doações particulares de roupas, móveis e cestas básicas (pedidas via telemarketing, por vezes), bem como de contribuições da família, da própria aposentadoria do idoso e de um convênio com a prefeitura do município, semelhante à instituição F, uma organização não-governamental que se diferencia apenas por não receber qualquer incentivo da prefeitura. A instituição $E$ denominou-se congregação e utiliza a aposentadoria das religiosas para sua manutenção. Todas possuem alvará de funcionamento. 
nstituições

\begin{tabular}{|c|c|c|c|c|c|c|}
\hline \multicolumn{7}{|c|}{ Instituições } \\
\hline & A & $B$ & C & D & $E$ & $\mathrm{~F}^{\star * *}$ \\
\hline \multicolumn{7}{|l|}{ N. ${ }^{\circ}$ de vagas } \\
\hline Homens & 0 & * & 0 & 0 & 0 & 100 \\
\hline Mulheres & 23 & * & 23 & 50 & 30 & 100 \\
\hline Casais & 0 & 0 & 0 & 0 & 0 & 0 \\
\hline Total & 23 & 30 & 23 & 50 & 30 & 200 \\
\hline Homens & 0 & 04 & 0 & 0 & 0 & 63 \\
\hline Mulheres & 18 a 19 & 16 a 20 & 22 & 49 & 26 & 82 \\
\hline Casais & 0 & 0 & 0 & 0 & 0 & 0 \\
\hline Total & 18 a 19 & 20 a 24 & 22 & 49 & 26 & 145 \\
\hline \multicolumn{7}{|l|}{$\begin{array}{l}\text { Distribuição } \\
\text { (segundo): }\end{array}$} \\
\hline \multicolumn{7}{|l|}{ Nível de } \\
\hline dependência & Não & Sim & Sim & Sim & Sim & Sim \\
\hline Outro & Sim & Não & Não & Não & Não & Não \\
\hline \multicolumn{7}{|l|}{ Faixa etária } \\
\hline 60 ou mais anos & 04 & 24 & 20 & 45 & 26 & 145 \\
\hline$<60$ anos & $14-15$ & 0 & 02 & 04 & 0 & 0 \\
\hline \multicolumn{7}{|l|}{ Nível de dependência } \\
\hline Independentes & 05 & 01 & 06 & 28 & 20 & 88 \\
\hline Dependentes parciais & $12-13$ & $19-23$ & 14 & 05 & 05 & 48 \\
\hline Dependentes totais & 01 & 0 & 02 & 16 & 01 & 09 \\
\hline
\end{tabular}

* Não é determinado de modo fixo um número de vagas para homens e mulheres na instituição $B$

** Por não saberem com exatidão, as instituições A e B forneceram estimativas

*** Foram considerados apenas os idosos assistidos (não-pagantes)

Figura 1 - Caracterização das instituições quanto a número de vagas, número de residentes, distribuição, faixa etária e nível de dependência dos idosos. Campinas, 2000

Quanto ao número de vagas, somente as instituições $\mathrm{D}$ e $\mathrm{F}$ oferecem mais do que 30 leitos. Tais vagas estavam quase totalmente preenchidas em todas as instituições. Quatro são voltadas unicamente à residência de mulheres ( $A, C, D$ e E), e nenhuma, a casais. Pudemos observar que há predominância de idosas, mesmo naquelas instituições que também acolhem indivíduos do sexo masculino. Tal fato, aliado à preponderância de locais destinados exclusivamente ao atendimento de indivíduos do sexo feminino, também é observado em outros estudos ${ }^{(10-11)}$.

A distribuição dos residentes nas instituições visitadas é realizada, segundo o nível de dependência, em todas as instituições, com exceção da A. Nesta, o quarto a ser ocupado é escolhido pela família. Somente aquelas que admitem idosos do sexo masculino é que utilizam o gênero como outro critério de distribuição (B e F).

Entre as seis instituições, apenas três admitem indivíduos com menos de 60 anos (instituições A, C e D), com grande parte deles na faixa entre 50 a 60 anos, o que contradiz a Portaria $810 / 89^{(6)}$, que considera como instituições para idosos aquelas que atendem pessoas com 60 ou mais anos de idade. Em todas, o número de indivíduos maiores de 60 anos prevalece sobre o outro grupo.

Quanto ao nível de dependência, em três instituições houve predomínio de indivíduos parcialmente dependentes ( $A, B$ e $C$ ), e, em outras três, de independentes ( $D, E$ e F). Vale destacar a instituição $D$ que possui 49 idosas, dentre as quais 16 totalmente dependentes. Esses dados apontam a necessidade de as instituições destinadas a idosos contarem com pessoas qualificadas para a assistência, visando ao atendimento das necessidades peculiares dos idosos, em particular dos mais fragilizados. Isso vai ao encontro das discussões atuais sobre a especialização de enfermagem em nível médio, que poderia ser contemplada com cursos de enfermagem geriátrica e gerontológica ${ }^{(12)}$.

\section{Recursos humanos}

Segundo o documento de caracterização e padrões mínimos de funcionamento das instituições 
geriátricas ${ }^{(13)}$, os recursos humanos mínimos necessários ao funcionamento das instituições asilares e suas respectivas cargas horárias são a assistência médica (10h semanais), assistência de enfermagem (24h/dia), assistência psicossocial (incluídos o assistente social e o psicólogo - 10h semanais), assistência nutricional (05h semanais) e assistência de reabilitação (que incluem o terapeuta ocupacional e o fisioterapeuta - $10 \mathrm{~h}$ semanais). A Portaria $810 / 89^{(6)}$ inclui ainda a necessidade de assistência odontológica, farmacêutica, apoio jurídico, administrativo, atividades de lazer e serviços gerais. Contudo, segundo dados obtidos, as instituições investigadas possuem somente os recursos humanos apresentados na Figura 2.

\begin{tabular}{|c|c|c|c|c|c|c|c|c|c|c|c|c|}
\hline \multicolumn{13}{|c|}{ Instituições } \\
\hline & \multicolumn{2}{|c|}{ A } & \multicolumn{2}{|c|}{$B$} & \multicolumn{2}{|c|}{ C } & \multicolumn{2}{|c|}{ D } & \multicolumn{2}{|c|}{$E$} & \multicolumn{2}{|c|}{$\mathrm{F}$} \\
\hline & N. ${ }^{\circ}$ & $\mathrm{H} / \mathrm{sem}$ & N. ${ }^{\circ}$ & $\mathrm{H} / \mathrm{sem}$ & N. ${ }^{\circ}$ & $\mathrm{H} / \mathrm{sem}$ & N. ${ }^{\circ}$ & $\mathrm{H} / \mathrm{sem}$ & N. ${ }^{\circ}$ & $\mathrm{H} / \mathrm{sem}$ & N. ${ }^{\circ}$ & $\mathrm{H} /$ sem \\
\hline Médico & 01 & $03 \mathrm{~h}$ & 02 & * & 04 & * & 01 & 02 a $04 h$ & 01 & * & 02 & * \\
\hline Dentista & 0 & 0 & 0 & 0 & 0 & 0 & 02 & * & 0 & 0 & 01 & * \\
\hline Farmacêutico & 0 & 0 & 0 & 0 & 0 & 0 & 0 & 0 & 0 & 0 & 01 & * \\
\hline Psicólogo & 0 & 0 & 01 & $18 \mathrm{~h}$ & 0 & 0 & 0 & 0 & 0 & 0 & 01 & * \\
\hline Fisioterapeuta & 01 & $08 \mathrm{~h}$ & 01 & $18 \mathrm{~h}$ & 0 & 0 & 0 & 0 & 0 & 0 & 01 & * \\
\hline Terapeuta Ocupacional & 01 & $08 \mathrm{~h}$ & 01 & $18 \mathrm{~h}$ & 0 & 0 & 01 & * & 0 & 0 & 01 & * \\
\hline Assistente Social & 0 & 0 & 0 & 0 & 0 & 0 & 0 & 0 & 0 & 0 & 02 & * \\
\hline Nutricionista & 0 & 0 & 01 & * & 0 & 0 & 0 & 0 & 0 & 0 & 01 & * \\
\hline Enfermeiro & 0 & 0 & 02 & $36 h$ & 0 & 0 & 01 & $36 h$ & 0 & 0 & 01 & * \\
\hline Técnico de Enfermagem & 0 & 0 & 0 & 0 & 01 & * & 0 & 0 & 0 & 0 & * & * \\
\hline Auxiliar de Enfermagem & 05 & $36 \mathrm{~h}$ & 0 & 0 & 04 & $40 \mathrm{~h}$ & 04 & $44 \mathrm{~h}$ & 03 & $56 \mathrm{~h}$ & * & * \\
\hline Auxiliar de cozinha & 02 & $36 \mathrm{~h}$ & 0 & 0 & 0 & 0 & 03 & * & 0 & 0 & 13 & * \\
\hline Faxineira & 01 & $42 \mathrm{~h}$ & 02 & $44 \mathrm{~h}$ & 0 & 0 & 06 & $44 \mathrm{~h}$ & 03 & $48 \mathrm{~h}$ & 15 & * \\
\hline Cozinheira & 0 & 0 & 01 & $36 h$ & 01 & * & 01 & * & 03 & $48 \mathrm{~h}$ & 03 & * \\
\hline Lavadeira/ passadeira & 0 & 0 & 01 & $44 \mathrm{~h}$ & 01 & * & 02 & * & 02 & $48 \mathrm{~h}$ & 06 & * \\
\hline Outros & 0 & 0 & $\operatorname{Sim}$ & * & Sim & * & Não & 0 & Sim & * & Sim & * \\
\hline
\end{tabular}

* Não soube informar

Figura 2- Distribuição do corpo técnico-administrativo das instituições, segundo carga horária semanal. Campinas, 2000

O número de profissional médico com que as instituições visitadas contam em seu corpo técnicoadministrativo é reduzido, e nenhum dirigente soube informar exatamente a carga horária semanal de trabalho desse profissional, afirmando, por vezes, que eles comparecem esporadicamente ou quando chamados. Muitos profissionais necessários para a assistência aos idosos, tais como enfermeiro, fisioterapeuta, terapeuta ocupacional, assistente social, nutricionista e psicólogo, estão presentes somente em algumas instituições (A, $B$, $D$ e F). Ademais, a instituição $B$ não conta com o auxiliar de enfermagem em seu quadro de pessoal.

A Resolução COFEN-146, de $1992^{(8)}$, estabelece, em seu artigo $1^{\circ}$, que "toda instituição onde exista unidade de serviço que desenvolva ações de Enfermagem deverá ter Enfermeiro durante todo o período de funcionamento da unidade". No entanto, apenas três das instituições pesquisadas ( $\mathrm{B}, \mathrm{D}$ e $\mathrm{F}$ ) contavam com esse profissional, presente somente em parte do dia. Desse modo, os dados sugerem que muitos procedimentos de competência do enfermeiro deixam de ser realizados ou são praticados por profissionais não habilitados legalmente.
Os outros profissionais citados foram: assistente administrativo e auxiliar de escritório (B), copeiras e ajudantes gerais $(C)$, motorista $(E$ e $F)$, eletricista, carpinteiro, porteiro, jardineiro, engenheiro e administradores $(F)$, além do atendente de enfermagem (C).

A criação, pelo COREN, da Câmara Técnica de Ensino e Pesquisa, que "acompanha, discute e propõe soluções que contribuam para a melhoria da qualificação dos profissionais de Enfermagem"(14) certamente é algo que pode colaborar na diminuição dessas distorções e no fornecimento de uma assistência de qualidade.

Outrossim, reforçamos a questão da especialização em nível médio, cujas discussões promovidas pelo COREN-SP ${ }^{(12,15)}$ deveriam também considerar a especialização em nível médio em enfermagem geriátrica e gerontológica, dada a especificidade dessa clientela.

Três dirigentes das instituições relataram possuir voluntários, entre eles, médicos na instituição $\mathrm{C}$, terapeuta ocupacional em D, e membros da diretoria em F. Em todas as instituições, os profissionais dispõem de espaço físico 
próprio e equipamentos para a realização de seus atendimentos, com exceção das instituições $A$ e $D$, nas quais o médico, fisioterapeuta e terapeuta ocupacional utilizam-se do próprio leito do idoso.

\section{Rotinas}

No presente estudo, foram consideradas as rotinas referentes à admissão, alimentação, higiene corporal e medicação.

Quanto aos critérios para a admissão de idosos, nas instituições pesquisadas, a idade é um fator de restrição para três delas ( $A, C$ e F). Nestas, a idade mínima para ingresso varia de 50 a 65 anos de idade.

Em relação ao nível de dependência, somente os dirigentes das instituições $\mathrm{E}$ e $\mathrm{F}$ o adotam como critério restritivo. Enquanto a instituição $E$ veda o ingresso de pessoas extremamente dependentes, a instituição $F$, segundo as respostas obtidas, restringe a entrada de indivíduos independentes. Chamou nossa atenção a falta de serviços que acolham as pessoas totalmente dependentes.

Embora nem todas as instituições adotem o critério de dependência, na admissão dos idosos, devemos considerar que o processo de envelhecimento leva ao comprometimento da capacidade funcional, determinando limitações para as atividades da vida diária e necessidades específicas, as quais exigem assistência de pessoal qualificado, com conhecimento sobre a senescência e sobre a importância da manutenção e promoção da autonomia e independência nessa faixa etária ${ }^{(16)}$.

De acordo com as respostas, são abertos prontuários ou outras formas de registro para cada ingressante na instituição, obedecendo à Portaria 810/ $89^{(6)}$, que recomenda a abertura de um registro de admissão e prontuários com dados não somente pessoais, mas também com respeito à capacidade funcional dos idosos, sua evolução, ações propedêuticas e terapêuticas.

Outros critérios de restrição foram apresentados como presença de distúrbios psiquiátricos (B, C e F), agressividade ou distúrbios de convivência social ( $A$ e $F$ ), uso de álcool $(F)$ e estado de terminalidade $(A)$, como observado em outros estudos ${ }^{(17)}$.

No que diz respeito à alimentação, as instituições apresentam horários rígidos que se devem à necessidade do enquadramento das demais atividades a serem realizadas no dia, implicando perda da liberdade do idoso.
Todas as instituições fazem uso de dietas específicas para residentes com hipertensão e diabetes. No entanto, algumas delas (A, C e D) oferecem o mesmo alimento a todos, justificando essa prática pelo uso de concentrações diminuídas de sal e gordura, não considerando as especificidades nutricionais de cada residente.

Quatro das seis instituições não permitem ao idoso servir-se sozinho ( $A, B, C$ e E), porém cada residente tem a liberdade de escolher a quantidade e o tipo de alimento entre as opções de cardápio de cada refeição.

Para a atividade relacionada à higiene corporal, todas as instituições preconizam o período da manhã, bem como consideram o nível de dependência no momento de sua realização.

Os idosos com comprometimento da sua independência são auxiliados por funcionários das instituições, os quais nem sempre são membros da equipe de enfermagem, ou seja, em algumas delas, não têm qualquer formação, fato que pode comprometer a saúde dos residentes, em decorrência do desconhecimento, quanto aos fatores de risco para acidentes, como engasgo e quedas, além de demais peculiaridades dessa faixa etária.

Quanto às medicações, os entrevistados de quatro instituições ( $B, C, E$ e $F$ ) afirmam seguir as prescrições médicas destinadas a cada idoso particularmente, sem estabelecer horários de rotina para administração dos medicamentos. A instituição $A$, por sua vez, realiza as medicações às 7:00h, 14:00h e 21:00h, e a instituição $D$, às 10:00h e 18:00h, e os horários das medicações de cada idoso adapta-se a esses horários estabelecidos.

Nos seis locais, os responsáveis pela administração dos medicamentos são os membros da equipe de enfermagem, a qual inclui o enfermeiro, o técnico e o auxiliar de enfermagem. Chamou nossa atenção a instituição $\mathrm{C}$, que indicou, como um dos responsáveis pela administração dos medicamentos, o atendente de enfermagem, ao qual, segundo a resolução COFEN-185, de $1995^{(8)}$, só é facultado o exercício de tarefas elementares. De acordo com essa resolução, tarefas elementares são "ações de fácil execução e entendimento, baseadas em saberes simples, ... não envolvem cuidados diretos ao paciente.... . Nesse contexto, entendemos que não compete ao atendente de enfermagem a administração de medicamentos. 


\section{CONSIDERAÇÕES FINAIS}

A população de idosos faz-se crescente, e as instituições de caráter asilar constituem-se, muitas vezes, na única opção para esses indivíduos e suas famílias. É necessário, portanto, que possuam aparatos infraestruturais, tanto em recursos humanos quanto materiais, para atender, convenientemente, a essa clientela, dadas as especificidades relacionadas à faixa etária.

As instituições pesquisadas caracterizaram-se por serem de caráter privado. Muitas delas não aceitam indivíduos extremamente dependentes ou mesmo demenciados, o que produz um déficit no atendimento desses sujeitos.

A presença de recursos humanos também é incipiente. Apenas um local demonstrou possuir todos os profissionais recomendados pela Portaria $810 / 89^{(6)}$. Entretanto, isso não garante a qualidade da assistência

\section{REFERÊNCIAS BIBLIOGRÁFICAS}

1. Decreto $n^{\circ} 1948$ Regulamenta a Lei $n^{\circ} 8.842$ de 4 de janeiro de 1994 - Política Nacional do Idoso e dá outras providências. Diário Oficial da República Federativa do Brasil. Brasília (DF): 5 jan. 1996. Seção 1, p.77-9.

2. Louzã MR Neto, Louzã SPR, Cohen C, Louzã JR. O idoso, as instituições totais e a institucionalização. Rev. Paul. de Hospitais 1986 julho/agosto/setembro; 34(7/8/9):135-43.

3. Vieira EB. Qualidade de vida na instituição. In: Sociedade Brasileira de Geriatria e Gerontologia - seção São Paulo. Consensos de Gerontologia. $1^{\circ}$ Congresso Paulista de Geriatria e Gerontologia; 1998. junho 24-27; São Paulo, SP. São Paulo: SBGG; 1998. p.62-5.

4. Ministério da Previdência e Assistência Social (BR). Lei $n^{\circ}$ 8.842 de 04 de janeiro de 1994. Dispõe sobre a política nacional do idoso e dá outras providências. Brasília (DF): Ministério da Previdência e Assistência Social; 1996.

5. Born T. Cuidado ao idoso em instituição. In: Papaléo Netto M. Gerontologia. São Paulo (SP): Atheneu; 1996. p.403-14.

6. Portaria $n^{\circ} 810$ Aprova as normas e padrões para o funcionamento de casas de repouso, clínicas geriátricas e outras instituições destinadas ao atendimento de idosos. Diário Oficial da República Federativa do Brasil. Brasília (DF): 22 set. 1989. Seção 1, p. 17297-8.

7. Duarte YAO, Pavarini SCI. Instituições de idosos: qualificação de pessoal. In: Sociedade Brasileira de Geriatria e Gerontologia - seção São Paulo. Consensos de Gerontologia. $1^{\circ}$ Congresso Paulista de Geriatria e Gerontologia; 1998. junho 24-27; São Paulo, SP. São Paulo: SBGG; 1998. p.66-73.

8. Conselho Regional de Enfermagem (SP). Documentos básicos de Enfermagem. Enfermeiros, técnicos, auxiliares. Principais leis e resoluções que regulamentam o exercício profissional de enfermeiros, técnicos e auxiliares de enfermagem. São Paulo; 1977. aos residentes. Ademais, não contando em seu quadro com os profissionais necessários, as instituições "cobram", de seus funcionários, o exercício de tarefas e a prática de atividades que extrapolam o grau de competência dos profissionais, além de causar sobrecarga com múltiplas funções e carga horária excessiva.

Diante do exposto, consideramos necessária a atenção e qualificação de recursos humanos voltados, especificamente, ao atendimento dos idosos, seguida da fiscalização por parte do órgão representativo dos profissionais da Enfermagem.

Outrossim, destacamos a necessidade de incentivo governamental, tanto em forma de verbas e isenção de impostos, quanto na criação de serviços de atenção terciária ao idoso, os quais Ihe possibilitem, ao menos, continuar sob o convívio familiar, o que, certamente, representa menores custos de atendimento dessa população.

9. Oficina discute especialização em nível médio. CORENSP 1999 maio/junho; 22:11.

10. Moreno AB, Veras R. O idoso e as instituições asilares no município do Rio de Janeiro. Gerontologia 1999 dezembro; 7(4):167-77.

11. Yoshitome AY. Avaliação da qualidade da estrutura de instituições asilares de uma região da cidade de São Paulo. [dissertação]. São Paulo (SP): Departamento de Enfermagem/ UNIFESP; 2000.

12. A especialização para o nível médio. COREN-SP 1999 janeiro/fevereiro; 20:6-7.

13. Fórum permanente da região sul. Política Nacional do idoso. Caracterização e padrões mínimos de funcionamento das instituições geriátricas. In press.

14. Leifert RMC. Fiscalizar também é ensinar. COREN-SP 1998 março/abril; 15:2.

15. COREN-SP monta estratégia para implantar processo de enfermagem. COREN-SP 1999 maio/junho; 22:4-5.

16. Pavarini SCl. Dependência comportamental na velhice: uma análise do cuidado prestado ao idoso institucionalizado. [tese]. Campinas (SP): Faculdade de Educação/UNICAMP; 1996.

17. Piloto AA, Nunes ATGL, Assis M, Frias SR. O asilo na cidade do Rio de Janeiro. Gerontologia 1998 março; 6(1):712. 